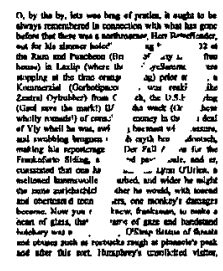

\title{
Bajtín, literatura comparada y sociocrítica feminista
}

\author{
M.-Pierrette Malcuzynski
}

\section{Universidad de Varsovia}

$\mathrm{E}$ n un intento de actualizar, con un máximo de potencia, la voz de lamujer, sin caer en la trampa de las diversas configuraciones de polarización binaria que, hasta hoy en día están vigentes aun en el seno de la teoría crítica contemporánea más radical, propongo trabajar la problemática del sujeto (tanto crítico como creador) desde una óptica específicamente sociocrítica. ${ }^{1}$ Es decir, no de manera «reactiva» frente a la axiomatización patriarcal y sus formas de división genérica desde un bloque hegemónico, sino dentro de los procesos interdiscursivos manifestados por y dentro del texto. Teórica y metodológicamente hablando, ya no es suficiente seguir dando cuenta de la evidencia de que el lenguaje, en sí, es portador de las instituciones (patriarcales), ni lo es el hecho de asumir, incluso de manera crítica. que la ideología (cultural) dominante-es decir, el discurso social-reduce el sujeto femenino a un discurso llamado 'minoritario.' Este trabajo tiene por objetivo exponer, a grandes rasgos, la formulación de una teoría sociocrítica feminista.

La sociocrítica surgió en la conyuntura intelectual francesa después de los Événements de '68 ante el callejón sin salida en el que habían caído los estudios literarios de la época, entre:

1) un sociologismo más y más rígido que, al sobreponerse a los varios neoformalismos y al estructuralismo entonces en vigor, presentaba todos los síntomas de replegarse sobre sí mismo y,

2) los de.sarrollos de la teoría literaria, suscitados por la influencia que los escritos de Jacques Lacan, el psicoanálisis neofreudiano y íos comienzos de la deconstrucción, a partir de los trabajos de Jacques Derrida y de equipos de

\footnotetext{
- Poligrafías 1 (1996) 23.43

Poligrafias. Revista de Literatura Comparada, Divisibn de Estudios de Posgrado, Facultad de Filosofía y Letras, Universidad Nacional Aut6noma de México, Ciudad Universitaria, México 04510 D. F.

Te!. (525) 622 1835(6). Fax (525) 622 1801; 6160047; 6221826.
} 
investigación (tales como el Grupo Tel Quel, reunido alrededor de Philippe Sollers y Julia Kristeva), ejercen en lingüistica y en crítica literaria, con una óptica que hemos aprendido a llamar desde entonces, posestructuralismo.

Dicho con más precisión: la sociocrítica se diferencia de la sociología convencional de la literatura por su objeto: el análisis del texto literario; lo que ha dado lugar a una reconceptualización importante de la noción misma de «texto.» Esta reconceptualización también demarca la sociocrítica de las perspectivas (neo)formalistas ya que, en palabras de Claude Duchet, se trata de restituir al texto de los formalistas su 'tenor' social. De modo que la sociocrítica intenta revalorizar el 'interior' del texto, descuidado por los sociólogos literarios, la organización interna de los textos, sus sistemas de funcionamiento, sus redes de sentidos, sus tensiones, el encuentro en ellos de diversos saberes y discursos heterogéneos (e! Edmond CroS).2 En este sentido, la sociocrítica abre un campo dinámico, tanto de investigación como de análisis textual, que busca el reposicionamiento, la reinserción del artefacto sociocultural, como el literario, y de su objeto de estudio, dentro de un conjunto de diversas práticas sociales en instancia de circulación y de interacción entre sí. De modo que, desde sus principios, la sociocrítica ha hecho una diferencia entre profundidad y sujeto psicoanal ítico, por una parte y, por otra, espesor social o socialidad del texto. Es decir: desde un punto de vista metodológico, la sociocrítica afinna que el autor o la autora no es jamás enteramente «dueño/a» de su discurso, no por razones psíquicas, particulares al individuo en cuestión, sino porque el discurso, el texto, el enunciado-la literatura-no constituyen esencias sino que desempeñan funciones dentro de coyunturas dadas que, de diversas maneras, condicionan las instancias de escritura y lectura. Otra premisa sociocrítica es que el sujeto sólo puede concebirse como sujeto/discurso por las interacciones con otros sujetos/discursos socioculturales. Eso no quiere decir que la sociocrítica refute en bloque los instrumentos de análisis puestos en circulación por el estructural ismo y el psicoanálisis, ni sus aportaciones, fundamentales a las técnicas contemporáneas para el trabajo sobre el texto. La sociocrítica se opone-al menos la sociocrítica que quisiera presentar aquí-al filtro prismático interpretativo que deriva de ellos, y se impone sobre la práctica literaria.

Por otra parte, ya que los comienzos de la sociocrítica coincidieron con las primeras traducciones de los escritos de Mijaíl Bajtín y su divulgación por los diversos mercados académicos, europeos y americanos (y que la mayoría de los sociocríticos leían sus obras), empecé a trabajar desde una perspectiva comparada sobre los posibles puntos de convergencias entre los dos. No se trata, claro está, de limitarse al examen de las influencias de formas y fuentes de una teoría o de una literatura sobre otra, sino de considerar los estudios comparativos/-tistas como un campo de investigación donde lo literario se 
presenta en sí mismo como una problemática fundamentalmentetransdisciplinaria,transem ióticaysociointerdiscursiva.

No obstante, si la así llamada literatura comparada nos ofrece directrices teóricas que conciernen a la producción literaria, no nos enseña mucho, en tanto que disciplina, respecto al análisis textual. De manera similar, si Bajtín nos da una teoría del discurso, en ninguna parte de sus escritos aparece una metodología propiamente dicha en cuanto a la formulación de modalidades analíticas operativas. Así nació cierta cantidad de nociones y conceptos operativos, algunos de los cuales se sobreponen, se traslapan, se entrecruzan y, en muchos casos, tienen origen bajtiniano. Basta con mencionar algunos que la terminología crítica contemporánea ha puesto en circulación desde hace varios años:

- sociograma, concepto forjado pero no elaborado por CI. Duchet (c! Robin/Angenot 1991 y Robin 1993);

- discurso social, concepto que, pasando por Michel Foucault, Robert Fossaert, entre otros, fue elaborado por Marc Angenot (1989) y R. Robin, partiendo de la polifonía de Bajtín pero distanciándose de ella;

- sociolecto y situación lingüística; Pierre Zima toma el concepto de 'situación' de corpus terminológico bajtiniano, pero sigue apoyándose sobre la lingüística saussuriana, por contradictorio que esto parezca;1

- campo lingüístico y campo cultural, esta vez en el sentido que lo propone el sociológo francés Pierre Bourdieu;

- ideosema (c! Cros 1986), una noción mucho más adecuada para el análisis del texto, desde mi punto de vista, que la de icleologema;

- campo morfogenético (siempre de Ed. Cros);

- «tiers interprétant» (c! Monique Carcaud, concepto con el que busca formular una teoría de la recepción sociocrítica);

- interdiscursividad: tal como ésta puede comprenderse en relación con «intertextualidad.» Lo 'intertextual' no tiene ningún sentido si uno no remite a las determinadas y variadas prácticas sociodiscursivas que atraviesan y sostienen el texto; es decir a la «interdiscursividad.» Añadimos las de complejo o nexo sociointerdiscursivo y monitoring que también propuse hace ya algunos años.

Ahora bien, si la sociocritica es una disciplina en vigor desde hace unos 25 años, ningún investigador, ninguna investigadora que se dice 'sociocrítico/a' ha desarrollado un discurso que de manera total tome en consideración la literatura femenina como objeto de estudio específico. ${ }^{4}$ Por eso tuve que empezar prácticamente de cero, con el primer objetivo de trabajar de modo muy preciso en la formulación de una teoría sociocrítica que respondiese a la problemática particular que presenta el examen de los objetos y los productos socioculturales cuando, por lo que concierne el texto literario, entre otros, el sujeto que habla y que escribe es una mujer. Desde luego, es imposible presentar este programa 
de inve,stigación en detalles; los diversos aspectos de la discusión tan sólo teórica, si bien no acabada aún, ya cubre más de cien páginas.

Mi hipótesis de una sociocrítica feminista se apoya en una combinatoria teórica de intersecciones tridimensionales, de la manera siguiente:

1) Algunos de los postulados de Mijaíl Bajtín, en particular los que remiten a la coyuntura 'comunicacional' del trabajo dialógico que sostiene y atraviesa el discurso;

2) Las modalidades metodológicas sociocríticasde base, que se relacionan con el trabajo de la heterogeneidad constitutiva de la realidad textual. Eso significa estudiar no sólo lo que un texto' dice' y cómo'dice lo que dice,' sino igualmente leer los 'blancos' de un texto, 'escuchar' sus silencios, poner en tela de juicio sus 'no-dichos' y, lo que no es la misma cosa, sus 'no-decibles,' sus 'inconfesables;' es decir, todo lo que Foucault definía en términos de lo que se puede decir 'aquí' y no 'allí,' y viceversa.

3) Algunas recientes orientaciones en teoría feminista, más específicamente la proposición de reformular la cultura desde una perspectiva feminista (lo que no debe confundirse con una supuesta 'feminización de la cultura') y que consiste en reemplazar el paradigma «la mujer como el otro» por «la mujer y el otro;» este 'otro' comprendido en un sentido amplio, ontológico y cognoscitivo del término. ${ }^{5}$ Lo interesante de esta propuesta es el potencial teórico de un trabajo sobre la conjunción $y$ del paradigma. A partir de la formulación de este nuevo paradigma no se trata de comparar, parangonar los elementos contiguos que emergen de prácticas diferentes, sino valorar críticamente las interacciones de sus funciones respectivas. La estrategia de base consiste en aprehender los objetivos interpretativos del paradigma y acentuar lo dialógico de su formulación con fines de colmar los riesgos de seguir efectuando una polarización binaria velada: la mujer de un lado; el 'otro,' delotro. ${ }^{6}$

Para activar el dialogismo de la proposición, sugiero volver a tomar el concepto del monitoring y desarrollar sus aspectos más pertinente para el estudio del discurso de la mujer. En parte fundado en la noción bajtiniana del umbral, el monitoring articula una intersección vital donde se actualiza lo interdiscursivo respecto de lo que está 'desemantizado' en y por el discurso. Se trata de un concepto operativo que permite llamar, de manera sociodinámica una coyuntura de multivocidad y resistir frente a las configuraciones constituidas por las formas de oposiciones maniqueístas, en particular las de naturaleza versus cultura, de lo privado versus lo público, etc., en las que se fundamentan las de feminino/masculino. Todas estas oposiciones desembocan en la exclusión y la relegación del sujeto femenino y/o feminista, aislándolo dentro de un proceso de auto-representación periférica-remito al fenómeno de desterritoralización (concepto de Deleuze/Guattari 1975). El concepto de monitoring también nos permite eludir la tentación de construir síntesis metafísicas a-genéri- 
cas que originan discursos 'antropófagos' o neutralizan los elementos de diferencia. La voz, pretendidamente, neutra, producto de la única verdad impersonal y monolítica, desde mi punto de vista, es un sofisma ridículo. Parler $n$ 'est\}amais neutre nos recuerda el título de la obra de Luce Irigaray.

Habría que desplegar el mapa multidimensional-hasta topográfico, diría-de lo que llamamos 'texto' y que, en otro trabajo yo he llamado, para subrayar su complejidad plural un nexo sociointerdiseursivo. Aquí interviene el monitoring, abriendo un espacio distintivo de lectura y análisis textual; interpela una serie de relaciones concretas, materiales e históricas de orden transemiótico y, de Jacto interdisciplinario, entre una práctica socioideológica definida y la práctica cultural, entre otras, literaria. Más que trabajar sobre los problemas (eternos) de la representación, quisiera proponer una revaluación sociocrítica de la constitución del sujeto y del discurso sobre la construcción de la identidad sociocultural; una lectura-que, fundamentada en la premisa bajtiniana de la heterogeneidad social de la circulación del lenguaje y de la comunicación, restituya al análisis una problemática cognoscitiva en el seno de una economía epistémica de 'responsabilidad.' Es decir, una lectura que dé cuenta del trabajo dialógico subyacente a la preeminencia de lo interdiscursivo sobre el discurso, que permita a los diversos usos de los discursos, ellos mismos de diferentes clases y categorías, recobrar sus prerrogativas.

Desde luego, la redistribución programática de las estructuras ideológicas que intervienen entre el poder y el saber dentro de la producción de la cultura, destacada por los estudios feministas, también pone en tela de juicio, de diversas maneras y en diferentes grados, un factor clave: el canon cultural. Ahora bien, si los estudios feministas han tratado de desmenuzar las formas (de representación) canónicas que revisten los objetos socioculturales; entendidas como reflejos de la ideología patriarcal, tan sólo recientemente comienzan a interrogar los fundamentos y los mecanismos del canon mismo en tanto que fenómeno regulador, especialmente en relación con la historia literaria y con las prácticas de lecturas que de ahí derivan (e! Díaz-Diocaretz y Zavala, coords., 1993). Ahora se pide y se ha puesto de moda que el canon no sólo se estudie, sino que se rescriba. En primera instancia, eso parecería lógico, en vista de la naturaleza de la lucha feminista, si se considera ésta como una forma de 'rescritura' que, además, no es ni ha sido nunca la exclusividad de la crítica literaria feministabasta pensar en la historiografía, un género constantemente rescrito, no sin riesgo. Desde el punto de vista metodológico y de sus objetivos en general, así como por sus modos de recuperación y de difusión o circulación de los textos literarios y otros productos socioculturales producidos por las mujeres, la proposición es, por tanto, riesgosa. El problema se hace agudo cuando se toma en consideración, tal como se anotó arriba, la construcción de la identidad. 
Prestemos atención: invertir, ni más ni menos los preceptos de la teoría de la dependencia, conlleva riesgos éticos y estéticos.

Reiteremos lo más evidente: si comprendemos por 'rescritura' la c.onstitución de un nuevo canon, no hay ninguna razón para crecr que sea éste intrínsecamente menos represivo que el precedente. Además, queda otro problema, el de reducir el análisis de los sistemas simbólicos en el nivel superficial de la productividad cultural y, por consiguiente, marginar o ignorar el hecho de que la cultura es una realidad vivida en sus interacciones concretas y materiales. Las manifestaciones culturales propiamente dichas-el texto literario, por ejemplo-resultarán descuidadas en el nivel de sus instancias de producción. Así se corre el peligro de olvidar el sujeto productor-quién escribe, para quién y a quién se dirige uno, desde qué espacio cronotópico (geopolítico, social, cultural, etc., y cuándo) escribe, cómo y, sobre todo por qué-y de concentrarse sobre el signo producido que, entonces, se encontraría navegando.' a la deriva. ' Tanto en el nivel de las teorías de la recepción como en el de las de la producción, las consecuencias pueden ser graves. Mucho más urgente es, me párece, trabajar sobre la formación y la estructuración de los discursos, a partir de los cuales. se articulan y se enuncian las formas de representación.

Recordemos rápidamente que la rama etimológica por la cual nos ha sido trasmitida la latinización del antiguo término griego de Kanón remite, en su sentido más amplio, a ciencias normativas en general y, aunque presente más la idea de una regla práctica o de un modelo por seguir, en sus usos más corrientes, es casi un sinónimo de 'norma.' Es esta idea de canon en tanto que precepto, regla, modelo, que se da al hablar en términos de 'canon bíblico' cuando el vocablo empezó a ser aplicado hacia el siglo IV de nuestra era,para designar algunos textos de los libros de la Biblia y una selección de los escritos de los primeros teólogos cristianos. Esta selección fue originalmente establecida con base en criterios dogmáticos, que pretendían distinguir lo ortodoxo de lo herético en materia de teología. En efecto, los escritos de los cristianos gnósticos tempranos (de los siglos I Y11) no aparecen en la versión final, alIado de los Evangelios o de las enseñanzas de Pablo y Timoteo. Vale la pena recordar que los escritos más influyentes de Agustín datan precisamente de la última década del siglo IV y las dos primeras del siguiente, en medio de un ambiente de cismas y herejías diversas.

Es de subrayar que el uso de 'canon' para designar una serie de textos o autores considerados como modelos, no es algo nuevo ni exclusivo, ya que los cristianos tan sólo adoptaron el uso del término que existía en la antigüedad clásica, bajo una forma u otra, para delimitar 10 que, desde una perspectiva deliberadamente muy amplia, hoy llamaríamos 'literatura.' Así, entre otros modos de clasificación, existe el Canon de Alejandría, establecido hacia los siglos I1I-11 a. C. por Aristófano de Bizancio y Aristarco, que reúne una serie 
de autores cuyos escritos constituyeron, por un tiempo, los modelos-ideales en la poesía épica, lírica, elegíaca, trágica, cómica, la historiografía, las artes oratorias y la fillosofía. Mas no es posible negar el hecho de que, en nuestras culturas occidentales de tradición judeocristiana, el 'canon bíblico' y su consecuente 'canon literario,' en el sentido moderno del término, se han dado la mano en el ejercicio del poder y en la pragmática de los conocimientos.

Por extensión, la 'religiosidad' inherente a la noción misma de canon, remite a una serie de 'textos sagrados;' concierne los modos y medios de legitimación de la cultura o, más precisamente, la selección de sus productos socioculturales según una escala autoritaria de valores. Se proyecta una connotación maligna sobre otra noción, la de tradición-y recordemos que uno de los usos modernos de 'canon literario' da cuenta de la 'gran tradición' de una literatura llamada 'nacional' ${ }^{8}$. lo que no deja de tener consecuencias cuando la misma se entiende como representativa de una colectividad y, a veces, de la 'memoria colectiva;' es decir, uno de los factores en los que se arraiga la formación de la identidad de un grupo o una clase. En todo caso, el fenómeno mismo de canon es un constructo que establece un modo de clasificación y, por lo tanto, una jerarquización de elementos constitutivos, paradigmáticamente fetichistas, que entablan sistemas regulados por rígidos mecanismos preceptivos de referencia.

Lo que me preocupa, al insinuar que una de las tareas del feminismo es la de rescribir el canon, no son tanto los componentes de un canon 'diferente,' como lo que encierra la noción misma de. canon. Cualquier modo de selección basado en los tajantes binomios exclusión/inclusión, negación/afirmación, etc., conlleva, desde el punto de vista de la crítica contemporánea, el riesgo de extraviarse en los laberintos del 'Otro.' En este sentido, creo que es inútil intentar recuperar y reapropriarse los componentes psicoanalíticos del discurso lacaniano desde una perspectiva feminista. Tanto esta concepción del 'Otro' como su derivado, también con mayúscula, la 'Otredad'-y me parece engañoso su género gramatical-siempre han sido de orientación patriarcal, cuando no 'masculinista' y difícilmente pueden conjugarse, conceptualmente, en femenino.

El fundamento epistemológico de una teoría sociocrítica feminista radica en la constitución del sujeto, según Bajtín, constitución que no implica únicamente lo que ocurre'dentro' (de la conciencia de uno mismo) sino que remite a lo que acontece en la frontera entre una conciencia y otra, en el umbral. Para Bajtín, el grado más alto de la socialidad está en el hecho de que cada experiencia interna, cada-sujeto, termina por encontrarse con un 'otro,' siempre sujeto/discurso. Toda la 'ontología' del 'yo,' en el sentido bajtiniano, es dialogizada en una frontera y se halla en este encuentro lleno de tensiones. Reafirmemos entonces que el sujeto es siempre el producto de interacción con 
otros sujetos socioculturales. «El acontecimiento en la vida de un texto,» por ejemplo, «es decir, su esencia verdadera, siempre se desarrolla sobre lafrontera entre dos conciencias, dos sujetos» (Bajtín 1982, 297). Hagamos un poco más precisa esta lectura de Bajtín:

Un acto creativo real del autor (yen general todo acto) șiempre se mueve en los límites (valorativos) del mundo estético, de la realidad de lo dado (la realidad de lo dado es una realidad estética), en la frontera del cuerpo, en la frontera del alma; el espíritu, mientras tanto, aún no existe; para él aún todo será; y todo aquello que ya es, para él ya fue. (Bajtín 1982, 180)

La palabra, dice Volóshinov, el discurso vive fuera del autor y no puede uno introyectarlo al autor. Lo que ha permitido a Jacqueline Authier-Revuz (1982, 119) profundizar la diferencia: el otro (interlocutor/discurso) es siempre, en Bajtín, el 'otro del otro' (interlocutor/discurso), de que se pueda decir que no hay 'otro' del 'Otro' (inconsciente).

En cuanto a las teorías sobre la constitución del sujeto; la escisión (el clivaje) psicoanalítica del 'yo' es una fórmula que permanece fuera del pensamiento filosófico bajtiniano. El concepto de heterogeneidad, en los escritos de Bajtín, está estrechamente ligado al dialogismo: en lugar de fusión, exclusión o sustitución-es decir, de deposición sistemática de un discurso por otro-implica acercamientos entre oposiciones 'y diferencias. La práctica dialógica se articula a partir de la interpelación recíproca de fenómenos aislados unos en relación con los otros, en un intento de no diluir sus propiedades o particularidades respectivas. Por el contrario, el dialogismo afirma la integridad de cada uno de ellos, dentro de una coexistencia dinámica y remite a la relación conjugadora del 'yo' y del 'tú,' del discurso del 'otro' en tanto que interdiscursividad. La fórmula 'yo como el otro' es ajena al pensamiento bajtiniano. El sujeto bajtiniano esfundamentalmente plural. En otras palabras:

«Va no es otrO»9 y si yo no puedo ser 'yo' sin estar conforme con la toma de conciencia del 'otro,' sujeto/discurso, pero que no es 'yo,' eso no quiere decir que el 'yo/mujer' no sea un 'yo,'sujeto/discurso con pleno valor: «Vo también soy» decía Bajtín.

Desde esta perspectiva, la práctica feminista nopuede ser reducida únicamente al trabajo sobre el 'otro' ni a la edificación de un nuevo canon cultural que se limite o sucumba a la tentación de reproducir, invirtiéndo los preceptos y mecanismos del paradigma patriarcal. «El problema más apremiante,» acertaba Toril Moi ya hace algunos años, «es cómo evitar el empleo de concepciones machistas sobre estética, historia y tradición al hablar de la 'tradición de las mujeres' ... » $(1988,91)$.

Ahora bien, solamente al perder su carácter exclusivo de 'dado,' según Mijaíl Bajtín, de 'museo' sugiere Walter Benjamin, desde una perspectiva algo 
diferente con respecto a la historia literaria, una ciencia puede sustituir lo ilusorio-o lo reflejado-por lo real. Para la óptica sociocrítica, eso significa examinar de cerca las interacciones, los procesos interactivos de mediación que distinguen, la semiotiZación de lo ilusorio, de lo real, si, por desafiar las fuerzas coercitivas del patriarcado y sus preconstrucciones genéricas, entendemos reorientar cabalmente la política institucional de legitimación y redistribuir el capital sociocultural. Más significantes, entonces, que la línea divisoria a partir de o sobre la que se (re)constituye un imaginario canónico, cualesquiera sean sus formas especulares de representación, son las estrategias socioideológicas que, al igual y junto a los procesos transemióticos negocian y potencian una prerrogativa diferencial. Me inspiro aquí en lo que significa un diferencial en matemática-la diferencia creada por el aumento infinitamente pequeño de una función, correspondiendo al aumento infinitamente pequeño de una variable-y en mecánica; es decir, un mecanismo que enlaza tres móviles, imponiendo entre sus velocidades simultáneas la condición de que cada una de ellas sea proporcional a la suma o a la diferencia de las otras dos. Estas dos definiciones nos aproximan al concepto de grado-cero de la dialogía y a la perspectiva desjerarquizante que .ofrecen las teorías bajtinianas sobre la polifonía literaria. En otros trabajos, sugiero que el «cero relaciones dialógicas,» este grado-cero bajtiniano, podía ser comprendido como el punto o uno de los puntos metodológicos de partida de la práctica sociocrítica (e! Malcuzynski 1989 y 1992, 80-84).

Según podemos inferir de las sugerencias bajtinianas, el concepto de gradocero parece designar una especie de cuarta dimensión en la dinámica tripartita de la dialogía, espacio donde Bajtín introduce el punto de vista de un 'tercero' que no participa formalmente en el diálogo sino que lo comprende. ${ }_{10}$ Desde la perspectiva cognoscitiva; aquí se materializa el abismo entre el 'intepretar' y el 'comprender' en el sentido bajtiniano de la palabra, o sea, entre 'interpretar' el mundo, considerar la diferencia como una entidad cerrada cuando no objetivada-por cierto, siempre plural pero abarcada en su aislamiento en tanto que 'otro/-a,' ajeno/-a-por una parte y, por otra, comprender la pluralidad del múndo en el sentido dialógico del término-desde dentro y mediante las interacciones de sus diferencias constitutivas. Dentro del marco de una teoría sociocrítica de la interdiscursividad, auiesgaría la idea de que las modalidades estratégicas del diferencial feminista articulan, mediante este grado-cero, una secularización del discurso.

Destaquemos en particular el hecho siguiente: 10 que ha sido traducido en los trabajos de Mijaíl Bajtín en términos de lo 'dado' y 10 'creado' se refiere concretamente a una serie de interrelaciones cognoscitivas que no son binarias, sino, al igual que la relación dialógica, fundamentalmenteJripartita. Lo 'dado' y 10 'creado incluyen lo 'planteado' ('posited' según las traducciones inglesas)- 
prefiero hablar de lo último en términos de lo 'proyectado,' en el sentido de 'proyección' (de horizontes ideológicos, epistemológicos)-donde, según Tatiana Bubnova, traductora de las obras de Bajtín al español, lo 'creado' sólo es posible en la frontera entre lo 'dado' y lo 'proyectado.' Áhora bien, lo canónico forma parte concreta de la categoría de lo 'dado' y, potencialmente, de las de lo 'creado' y 'proyectado.' Por otra parte, en el nivel de la textualización, lo diferencial se articula o se enuncia a partir de la interacción de lo ideológico y lo semiótico, de acuerdo con el estatuto y la función sociohistóricas inmediatas del sujeto, en el seno de la polifonía discursiva. Aquí estamos en el centro de la problemática de la producción del sentido que aparece, entonces, como una especie de cuarta dimensión en la tríada dialógica. El sentido siempre es una variable coyuntural. Desde una perspectiva dialógica bajtiniana, el sentido no es el punto de vista objetivado, borroso, transhistórico, asimilable a una 'Verdad' simbólica de significación, paradigmáticamente impersonal, es decir, 'universal,' supuestamente neutro. El sentido no es una categoría cuantificable; tal como la ideología, es sólo identificable, pero eso no se debe al hecho de que el discurso se presente como un espacio sin fronteras, un topos que transgrediera todos los límites (definición querida por los posmodernistas), sino porque el discurso es, en sí, unafrontera. El matiz puede parecer sutil pero no es menos fundamental. El discurso es una frontera porque en él se entrecruzan múltiples puntos de vista coexistentes, pero que provienen de-diversos horizontes epistemológicos, y llegan a constituir una coyuntura discursiva determinada. En el seno de esta coyuntura, sociopolifónica, el sujeto, usuario de los discursos y estratega, siempre toma posición.

La noción de imaginario canónico necesita, evidentemente, un desarrollo ulterior, imposible de discutir aquí. Me limitaré a decir aquí que, según mi concepción, lo imaginario canónico es una categoría residual de lo 'dado' y que, según la orientación ideológica del sujeto, está asimilada o descartada por los procesos de textualización, mediante los ideosemas. Digo ideosema y no ideologema. El ideosema es un concepto acuñado por Edmond eros y designa cualquier fenómeno textual, situado en la intersección de lo ideológico y lo semiótico (a diferencia del ideologema, definido por la teoría como el producto de la asimilación de lo semiótico por lo ideológico), que produce o reproduce las diversas interacciones entre los diferentes discursos coexistentes en una misma instancia social dada. De manera que, en sus aspectos asimilados o ,descartados, el contenido canónico de lo imaginario siempre forma parte integrante del texto. El ideologema, en cambio, remite a factores que permanecen fuera del texto. Podríamos asumir que lo canónico es lo 'no-decible' de toda formación imaginaria y, como tal, se identifica con el habitus de su discurso. 
Aquí tenemos otra noción, extremadamente compleja y que, además, debe ser considerada como un arma de doble filo. Me limito a recordar la definición que Robert Fossaert (1983, 103 Y 105) da, a partir de algunos trabajos del sociólogo Pierre Bourdieu.

Habitus, habitude, ces mots apparentés disent-ils la même chose? Dui, mais avec une force différente. L'habitude, mot banal, peut désigner des coutumes ancestrales ou des usages récents, des façons individuelles ou des pratiques collectives, mais toujours elle vise un petit domaine à moins qu'elle ne désigne, in abstracto, une faculté supposé de I'homme. L'habitus, mot savant, a un sens plus précis et plus ferme. 11 désigne le systeme complet des habitudes que l'éducation et l'expérience enracinent en chaque homme, sa capacité de «digérer» des expériences nouvelles, sa compétence culturelle.

Precisa también que el habitus es el aprendizaje de 'lenguajes' que son diferentes de la lengua 'natural:'

au fond, chaque habitus me parait être cela: un 'langage' plus ou moins spécialisé qui régit un pan du discours social, une part des usages verbaux et gestuels, parlés et agis, communément usités de quelque partie de la société (nonobstant la charge imaginaire qu'y investit chaque individu) ... l'habitus dit l'inertie des hornmes rangés en leurs diverses formes de convivance et l'immense travail pédagogique que les A[ppareils] I[déologiques] doivent opérer pour vaincre cette inertie ou, mieux, pour la retoumer en leur faveur, en inscrivant leur intluence dans leshabitus de leur publico

Cuando la contigencia genérica está entendida como una categoría de análisis de la constitución del sujeto, la institución del patriarcado aparece en tanto que el habitus con múltiples ramificaciones.El habitus patriarcal se hace visible al realzar los dos pasos.cognoscitivos por los cuales el sujeto. se constituye cuando es una mujer la que habla y escribe, en particular, cuando estructura su identidad en torno a un discurso específicamente feminista: Primero-y al contrario de lo que nos han enseñado Louis Althusser y, a partir de él Michel Pecheux, ellos mismos basándose en las teorías de Lacan". recordando (subrayo) el hecho de que las 'voces' que articulan la hegemonía patriarcal desde el interior del discurso, son las mismas que enmarcan, dirigen y legitiman, desde fuera, las estructuras discursivas oprimidas, a veces llamadas 'minoritarias,' frente a las supuestamente 'mayoritarias,' del discurso social. Segundo, tal vez aun más importante, recordando que, al reconocer las formas de su propia contradicción interna, el stijeto tiende a marginalizarse y a proyectar al exterior aquel constructo binario que es esencial a esa axiología hegemónica, cuya ideología constituye el fundamento de nuestra epistemología occidental, y que, en su versión posmodernista, ha sido coagulada en términos de 'ambivalencia,' de 'paradoja' y 'ambigüedad,' etcétera. ${ }^{12}$ 
Hagamos un paréntesis para reflexionar algo más sobre la diferencia que hemos observado arriba, entre los dos enunciados: «el discurso no tiene fronteras,» por una parte, y por otra, «el discurso es una frontera.» La cultura y sus objetos no pueden considerarse objetos de cambio, transferibles o 'diferibles,' de un sistema de referencia a otro. En parte basado en las lecturas e interpretaciones de Julia Kristeva del dialogismo, de la polifonía y de la carnavalización de Bajtín, el problema consiste en lo siguiente: releer el idealismo monológico hegeliano mediante un prisma psicoanalítico (lacaniano) no podía sino traer como consecuencia una supuestamente 'nueva' dialéctica que debía celebrar un sincretismo freudomarxista triunfador. En lugar de esto, sin embargo, la teoría ha sido testigo de la entronización de este Otro supremoademás, siempre 'suyo,' jamás 'suya'-que alcanzaba a canonizar Lacan como un Nietzsche magistral contemporáneo pero vuelto al revés. Hago referencia a esta óptica perfectamente ahistórica, basada en una ruptura interna, paraesquizoide, fundamentada en una problemática del subconsciente, a la vez que vehiculada por una pseudometafisica: mirada en pánico del Super Yo, en tanto que reflejo estructural de un deseo que no puede o que ya no puede alcanzar su objeto. y así apareció una confusión masiva entre la producción de la cultura, de un lado, y los sistemas simbólicos de laproductividadtextual, del otro. Hablo de los excesos de un discurso analítico que se paralizó en un nivel narcisista teorizante, obsesionado por los elementos figurativos del lenguaje y el pathos de los tropos que difieren y diseminan el sentido. Un discurso que re-emerge como un arrogante regreso de lo reprimido (refoulé) para exhibirse en términos de 'universales' globales y que privilegia la cáscara desemantizada del signo en detrimento de los acontecimientos concretos, sociohistóricos-Ia idea también es algo concreto-a los cuales, no obstante el signo, remite, siempre y sin excepción.

Ante y sobre todo, por teoría sociocríticafeminista querría designar una práctica irreductible a las modalidades monolíticas que ella misma confronta; modalidades que, en nuestra época así llamada 'pluralista,' quizás más que en otra, pero de ningún modo exclusivas de ella, fundamentan su eficacia al apropiarse de lo diferencial como suyo propio y, al mismo tiempo, desde la perspectiva de esta misma hegemonía, asientan, o sea'canonizan' los márgenes en tanto que orden legítimo y aceptado como tal. ${ }^{13}$ Frente al aparente callejón sin salida, es necesario reorientar el enfoque crítico para poder destacar cómo, al estructurar su socialidad, el sujeto plantea la tensión inherente de la heterogeneidad y logra reconfigurar la relación comunicacionallsignificante. Más que intentar en vano forjar un 'nuevo lenguaje,' me refiero a una política sociocrítica que entable, tal como se ha apuntado anteriormente, una hermenéutica responsable de mediación cultural. Es decir, una hermenéutica que 'des- 
colonice' la problemática genérica impuesta por el patriarcado, para poder 'desmarginalizar' el sujeto femenino sin neutralizar su toma de posición.

En cuanto a los procesos de textualización, esta toma de posición se enuncia dialógicamente, para recobrar una prerrogativa cronotópica que radica en la conjugación de lo que he llamado ya-existente y lo que todavía-no-es. ${ }^{14}$ Entendamos esta conjugación no como un especie de coqueteo con un cierto voluntarismo dogmático, sino como una manera de (re)pensar el mundo; se trata menos de atacar o negar que de concebir horizontes diferenciales. Un poco de utopía, que yo sepa, nunca ha hecho daño. En otras palabras: todos sabemos que el cambio no puede abordarse en términos de una división entre el poder y el saber, sino desde una óptica que pone en relación el ejercicio del poder y la adquisición del saber. Yeso significa confrontar algunas opiniones que afirman que el cambio no es visible sino como un aposteriori y unfait accompli. Ahora bien, si podemos decir que el cambio no puede ser asumido sino, efectivamente, desde una perspectiva retroactiva, pienso que, sin embargo, no sólo se debe buscar circunscribir los factores que potencian el cambio, sino que el cambio en sí puede ser identificado en la inmediatez de su manifestación. Es en este nivel cognoscitivo que se opera una reterritorialización.

Se perfila, entonces, la posibilidad de concebir una semiosis diferencial donde los campos de conocimiento y de experiencia no se desavengan recíprocamente, según los principios de la escisión, el clivaje de la semiología tradicional. Y no olvidemos que las formas manifestadas de esta escisión-habitus negativo semiológico del fetichismo de la lingüística-proyectan una dicotomía maniqueísta, que, en sus formas binarias de representación, sirven de fundamento y razón al poder que la noción misma de canon ejerce sobre la legitimación de la cultura, así como, sobre la formación y la circulación de los discursos.

Bajtín escribía en su primera publicación conocida 1919, que «El arte y la vida no son lo mismo, pero deben convertirse en mí en algo unitario, dentro de la unidad de mi responsabilidad,» fundamento ético, luego elaborado en distintas direcciones estéticas, en particular en otro artículo temprano, «El problema del contenido, del material y de la forma en la obra literaria» 1924. Para dar vigencia a estas palabras, quisiera volver a tomar una sugerencia de Walter Benjamin (1971-1983, 148), la de considerar la literatura como un órganon de la historia. Recordando lo que el órganon significaba en palabras de Aristóteles en sus tratados de Lógica, nos permite abordar la literatura como un instrumento, un sistema de demostraciones que ayuda a organizar un cierto proceso racional de conocimiento. En este sentido preciso, Francis Bacon empleó el vocablo latino, en su Novum Organum, referiéndose al saber y al razonamiento científicos. Tal aproximación a la pragmática de los saberes difiere radicalmente de lo que sugiere la noción de canon que muy bien se resume en las 
palabras siguientes de Leibniz: «llamo cánones a unas fórmulas generales que ante todo ofrecen lo que uno pide o busca.» Queda por precisar, claro está, quién pide qué y en qué contexto. La diferencia se hace aun más clara al recordar el cánon musical, ya que junto al advenimiento y los desarrollos de las teorías contrapuntísticas de composición, en plena época medieval,el término se asimila aquí a la noción de repetición, de manera análoga a la definición que hemos visto de 'norma' o modelo por seguir. El canon musical consiste en la imitación rigurosa de un canto principal dominante (el antecedente) por una segunda o más voces (consecuente/s) que entran una tras otra sucesivamente, al unísono o a intervalos regulares superiores o inferiores. La melodía principal es la que da la regla y el paso a todas las otras que deben imitarla, nota por nota.

En este nivel de asociaciones teóricas musicales, pienso tatnbiénen otro desarrollo del contrapunto y que viene a constituir técnicamente la polifonía: es decir, una multiplicidad de voces que cantan al mismo tiempo melodías diferentes y cuyo principio de organización Mijaíl Bajtín recoge, mucho más escrupulosamente de lo que parece a primera vista, al concebir y definir el discurso polifónico literario a partir de su lectura de la novela dostoievskiana, oponiéndolo al discurso monológico (o la monodia musical). Es de notar, sin embargo, que algunos instrumentos de la época, los de cuerda por ejemplo (la lira, el arpa) o los, que se basan en los mecanismos de un 'hidráulico'-el futuro órgano-producen el efecto de concordancia de varios sonidos que multiplican los armónicos de una voz simple o monódica. Semejante efecto se produce al juntarse varias personas que cantan en tesitura diferente, o cuando un cantor está acompañado por un instrumento que no repite idénticamente la melodía que canta la voz. El primer tratado de música que hace referencia, de manera clara, a la posibilidad de componer canciones para diversas partes, data de la segunda mitad del siglo VII, pero hay que esperar hasta los finales del siglo IX para que aparezca'una definición y explicación teórica de las técnicas polifónicas. Basada en la doctrina pitagórica de las consonancias, la técnica de la diaphonia consistía en la concordancia simultánea de dos voces o grupos de voces que cantaban horizontalmente la misma melodía en una tesitura diferente. La vox principalis designaba la melodía principal o canto llano, mientras que la vox organalis era la que reproducía simultáneamente en un intervalo dado, la melodía a modo de acompañamiento a la voz principal. ${ }_{15}$ En otras palabras, la palabra latina de órganon, el organum designaba originalmente una partida cantada a un cuarto o quinto de intervalo como acompañamiento a la melodía principal (cuando el intervalo de la tercera aparece en la técnica de composición, se habla ya de polifonía propiamente dicha).

Aquí es donde, desde el punto de vista teórico, veo todo un mundo de diferencia, toda una ideología musical diferente, para no decir diferencial entre, por un lado, el mecanismo de repetición cuya función, en el canon, es la de 
imitar (no sin recordar los preceptos ortodoxos de la antigua mimesis) y que confiere a la melodía principal su especificidad irrefutablemente idealy, por otro lado, el órganon, el principio que rige, en una primera etapa del desarrollo de la polifonía, la noción de acompañamiento a un canto principal. Esta función de acompañamiento es determinante para la historia de la teoría musical, ya que la consonancia es un fenómeno cambiante que, potencialmente, puede convertirse poco a poco en disonancia según las leyes de la evolución del oído. Este hecho vale la pena observarse cuando, además, se sabe que las técnicas contrapuntísticas de composición se orientan progresivamente hacia una mayor libertad de movimiento melódico, hacia la posibilidad de diversificación vocal respecto al tema musical principal, hasta desembocar en la polifonía propiamente dicha. Ý, la nota de interés es que en el siglo XIV, cuando en España el organum tomó el sentido general de polifonía, el llamado «canto de órgano» significa, ni más ni menos, canto polifónico.

Considerada en relación con la de canon, la propuesta de un organon literario sugiere posibilidades de pensar la labor intelectual y discursiva en términos de una cultura que' canta' o 'habla' la historia, abriéndola a diferentes 'voces' en su relación vivida en interacciones-en cierta medida la historia cantada sobre un registro diferenciado-ya que por ello significa reconocer la división de la labor estratégica del discurso, no con respecto a la historia (patriarcal), sino dentro de la actualización histórica. De este modo, se puede configurar un registro de práctica feminista sobre una base diferencial que, de acuerdo con su situación sociohistórica inmediata, reorienta los procesos simbólicos de identificación del discurso en lo que concierne al sujeto y sus objetos. Esta reorientación, a mi modo de ver, subraya el carácter fundamentalmente secular-en el sentido 'desacralizante'-del discurso feminista. Un último detalle, sacado de algunos estudios sobre los orígenes de la polifonía musical, apoya la hipótesis del proceso de secularización discursiva: parece que la polifonía tiene raíz en lamúsica folklórica tradicional (e! Belaiev1933, citado por Reese 1989, 301). La línea divisoria entre una música folkórica unísona y supuestamente 'natural' y una polifonía' cultural' sería un puro invento teórico parajustificar, para no decir legitimar,postfactum el hecho de que, en el periodo gótico fue la Iglesia la que cultivó las técnicas polifónicas con mayor intensidad que los trovadores en la música profana. Además, es también la Iglesia la que, en la música sagrada litúrgica, confiere a la técnica del organum (ya a finales del siglo IX) la función de ornamentar el canto y de embellecer el repertorio gregoriano. Esta función, parecida a la de los tropos en el discurso, viene a confirmar la temprana canonización del binomio naturaleza/cultura, aun dentro de un dominio tan abstracto como el de la música.

Esta breve excursión en el terreno de la teoría musical-excursión que me gustaría tratar como un pequeño ensayo transdisciplinario de literatura com- 
parada-no resulta gratuito, si la tomamos desde el punto de vista de una proposición sugestiva sobre el valor cognoscitivo, transformador de la práctica cultural. Después de todo, tal como lo apuntan los musicólogos, el surgimiento de la polifonía medieval es, históricamente, el producto de la convergencia de dos hechos musicales; dos técnicas de composición musical, conceptualmente muy diversas y hasta contrapuestas: la técnica instrumental y la vocal. En este sentido, es el aspecto heterogéneo de la polifonía que interesa a Bajtín, el que remite a la cohabitación y la circulación de múltiples 'voces,' de múltiples sujetos/discursos diferentes, de varias categorías semióticas verbales y no verbales, y de distintas clases, en interacción dialógica entre sí. y ¿qué decir de la reflexión de Gustav Mahler-contemporáneo o casi, de Dostoievski-cuando afirmaba que la «auténtica» polifonía (Mehrstimmigkeit) no es una simple pluralidad de sonidos (Vielstimmigkeit) o sea, según Mahler, una «homofonía enmascarada,» sino el producto de la confrontación de sonidos de diferentes naturalezas, musicales y no musicales? Eso, sin hablar del hecho siguiente: lo que a Malher le gustaba en esta definición de la polifonía, según Theodor Adorno, era el insulto al «formalismo» (musical).16 Todo ello no quiere decir que, como afirman algunos críticos, la novela sea un género intrínsecamente 'polifónico': bien se ha esforzado Bajtín en explicarnos lo contrario. La polifonía ha servido a Bajtín, no sólo de metáfora conceptual para describibM identificar 'narratológicamente' si se puede decir así, la novelística dostoyevskiana, sino también para sugerir, en la «Conclusión» de su libro sobre Dostoievski, «que se puede hablar directamente acerca del pensamiento artístico polifónico que traspasa los límites del género novelesco,» un tipo de pensamiento, añade Bajtín, «capaz de alcanzar tales aspectos del hombre-ante todo, la conciencia pensante del hombre y la esfera dialógica de su existenciaque no son abarcables artísticamente desde una posición monológica» (1986, 376). Aparte de lo que eso nos sugiere con respecto de la concepción misma de la noción de 'género' (literario o no), el pensamiento de Bajtín acerca de la cultura literaria constituye en sí mismo un discurso, teórico, sociodinámico, 'participativo,, 'interactivo,' eminentemente transdisciplinario. Es un discurso complejo, literalmente, que se abre sobre y se mueve, concretamente, entre la filosofía del lenguaje y de la estética, las teorías literarias y las que hoy llamamos culturales (por ej., el carnaval, un espectáculo gestual, sincrético y ritual, nos dice Bajtín); un discurso que se nutre de préstamos de las ciencias «puras» (la biología y la física cuántica, en relación con su noción del 'cronotopo,' por ejemplo)!? y de la teoría musical (las técnicas polifónicas de composición), préstamos que cumplen funciones, en los escritos de Bajtín, mucho más fundamentales que meramente metafóricas ${ }_{\text {o. }}$ Todo su pensamiento es sociointerdiscursivo en el sentido fuerte del término; remite a la heterogeneidad constitutiva de cualquier discurso que, para ser com- 
prendido no puede abordarse sino desde una perspectiva literalmente multidisciplinaria.

El órganon literario feminista se presenta entonces como un proyecto 'naturalmente' heterodoxo que deslegitima la brecha contradictoria, 'doblemente enlazada' de la autoritariajerarquía entre el discurso cultural y la historia. Este proyecto se hace visible como un monitoring de nuevas relaciones dialógicas entre los registros de la partitura histórica para localizar el punto gradocero, lugar donde la socialidad, o «entonación,» en metáfora bajtiniana, cambia de rumbo y compone una nueva realidad melódica. La tarea interactiva consiste en destacar cómo los productos culturales de autoría femenina ofrecen las posibilidades de generar posiciones socioideológicas que abren los límites impuestos, dando lugar a la práctica, no tanto de una (poética de) negación como de una afirmación reivindicativa, genuinamente histórica. Consiste en una práctica, cuyo proceso de secularización discursivo desenmascara el sistema mitológico, no solamente de lo no-dicho de la razón genéricamente determinista, sino también sll espejo deformador no-decible que, al trastornar las relaciones y proyectar una imagen invertida de las formas hegemónicas, recupera las mismas y perpetúa sus propios constructos.

La elaboración de una teoría sociocrítica feminista gira en torno de una hermenéutica dialógica que permite inscribir la pluralidad de distintas voces sin reconciliar las mismas en una sola, única identidad monolítica sino, al contrario, valora las especificidades de sus funciones respectivas. En definitiva, creo que la práctica feminista comprendida en estos términos tal vez constituya, detodos los discursos de desritualización y desfetichización, la fuerza más potente de emancipación, por lo que concierne las relaciones de poder entre el discurso normativo de la problemática canónica y la pragmática de los saberes dentro de la producción y la circulación socioculturales.

\section{Notas}

1 Este texto presenta algunos de los aspectos teóricos de una investigación actualmente en progreso, en teoría sociocrítica acerca a la formación de discursos femeninos y/o feministas en las culturas literarias hispánicas. De hecho, se inspira y se apoya en varios ensayos ya publicados o en prensa (véase las referencias para una selección bibliográfica), a la vez que revisa algunas de las propuestas expuestas anteriormente, omite tal o cual punto o hace hincapié en otros aspectos aún no desarrallados.

2 Véase los artículos incluidos en Ma1cuzynski, ed., 1991, yeros, 1986.

3 Para una crítica de la postura crítica y los argumentos de Pierre Zima, véase mi discusión en 1991, ed., 11-28.

4 Es más, la reacción-aunque, por supuesto, no unánime-de los sociocríticos tendía hacia la opinión de que un discurso teórico feminista desde 'dentro' de la sociocrítica no era 'necesario.' 
5 Myriam Díaz-Diocaretz $(1989,126)$ propone una crítica que «se sitúa en el entrecruce de una critica feminista que considera el lenguaje como un fenómeno nq-determinístico y la teoría de la comunicación de Mijaíl Bajtín» (consúltese también «El sociotexto: el entimema y la matriherencia en los textos de mujeres» incluido en Malcuzynski,ed., 1991, 129-144 Y'La palabra no olvida de dónde vino.' Para una poética dialógica de la diferencia» en el volumen colectivo que coordina con 1. M. Zavala 1993,77-124). M. Díaz-Diocaretz es una de las pocas críticas feministas que, en lugar de aplicar las modalidades bajtinianas tal cual, de manera más o menos mecánica, a textos firmados por mujeres, vuelve a tomar algunos de los postulados teóricos de Bajtín y los (re)trabaja desde una perspectiva crítica específicamente feminista.

6 Es en ese sentido que me parece insuficiente la proposición-no obstante, muy sugestiva-de Díaz-Diocaretz de estudiar (tan sólo) «este 'otro' en el discurso, así como también las 'voces,' las formas, las correlaciones y los contextos de este 'otro,' cuando el sujeto que habla y escribe es una mujer» (en Malcuzynski, ed., 1991, 136).

7 Propuse este concepto en una ponencia leída en un coloquio sobre Bajtín en Dubrovnik (abril de 1989), publicada en versión aumentada (Malcuzynski 1990). Véase también 1989 así como las demás referencias bibliográficas, en particular 1991, ed., 151-174 y 1995c. Con respecto al término mismo, valga mencionar que me inspiré en el título de un programa de la Televisión Nacional Polaca, «Monitor»-un one-man show que comèntaba acontecimientos de política nacional e intemacional-y que gozó de considerable popularidad durante su difusión en los años sesentas.

8 Para Terry Eagleton $(1983,11)$, el canon literario es «la 'gran tradición,' no cuestionable de la 'literatura nacional.' $)$

9 Invierto deliberadamente la célebre frase de Arthur Rimbaud, <de est un autre,» y que Philippe Lejeune ha vuelto a tomar como título de su estudio sobre la aytobiografía.

$10 \mathrm{Me}$ baso en la traducción francesa del artículo de M. Bajtín, «Le probleme du texte» incluido en Esthétique dé la création verbale (1984): «Le degré zéro du rapport dialogique. C'est là qu' apparaít clairement le point de vue du troisieme dans le dialogue (de celui qui ne participe pas au dialogue mais qui le comprend)o La compréhension du tout de I'énoncé est toujours dialogique» (335). Mientras que la versión inglesa del mismo fragmento es casi idéntica, la española es ligeramente diferente: «Cero relaciones dialógicas. Aquí sè revela el punto de vista del tercero en un diálogo (que no participa en él, pero lo entiende). La comprensión de un enunciado completo siempre es dialógica» (Bajtín 1982, 317).

11 Me refiero, en particular, a la «teoría de los dos olvidos» de Michel Pecheux (1975a y b) y el problema de la ilusión subjetiva, es decir, «la ilusión para el sujeto de ser la fuente del sentido.» Habría que reiterar los peligros de esta forma particular de pensar, doblemente reprensible, por ser a la vez genética y genérica (no gender aquí, sino genre): llevado a sus extremos, este procedimiento analítico puede conducir, de manera insidiosamente implícita, a la idea de que el texto no existe; lo que existe es sólo la 'interpretación.' Queda por hacer un trabajo teórico que haga una distinción entre lafuente del sentido y su producción, de manera que replantee la problemática de la preeminencia de lo interdiscursivo sobre el discurso en un marco claramente 
bajtiniano. Aquí también convendría recordar, al margen de las teorías de Lacan, la teoría freudiana de la seducción tergiversada en complejo de Edipo.

12 Subrayemos una vez más, aquí que la 'indeterminación,' en tanto que concepto, no es un sinónimo de la 'diferencia' ni aun menos de la 'diferencialidad;' así como el de 'diseminación' no refiere ni se identifica con el de 'diversidad polifónica.'

13 Referiéndose a una sociedad dependiente de una «condición postmoderna»-en la que «notre vie se trouve voué ... à l'accroissement de la puissance. Sa léginlitation en matiere de justice sociale comme de vérité scientifique serait d'optimiser performances du systeme, l'efficacité.» Hace ya casi 15 años Jean-François Lyotard $(1979,8)$ calificaba este fenómeno de recuperación, de «paralógico:» es decir, una legitimación «commandée ou en tous cas utilisée par le systeme pour améliorer son efficience» (98-99).

14 Posteriormente a estas reflexiones, he leido el ensayo de Sigrid Weigel, «La mirada bizca: Sobre la historia de la escritura de las mujeres» (en Ecker, ed., 1986, 79-98), donde habla de la necesidad de la mujer, para poder vivir en lo que Weigel llama «el espacio transicional entre el ya no y el todavía no,» de aprender a ver con «el rabillo del ojo» $\mathrm{y}$ «mirar en dos direcciones divergentes simultáneamente debe aprender a expresar las contradicciones, a verlas, a comprenderlas, a vivir en ellas y con ellas, y también aprender a ganar fuerza de la rebelión contra el ayer y de la anticipación del mañana» (88-89). Aproxima este ya no y todavía no a la perspectiva de Julia Kristeva para quien la praxis feminista debe ser necesariamente negativa «para ser lo no ser»» (1977 y 1979). Y aquí hallamos el double-bind psicoanalítico, esencialmente negacional. Tal como lo he apuntado en trabajos anteriores, no comparto el punto de vista kristeviano; la conjugación de lo ya-existente y lo todavía-no-es, más que una negación implica una afirmación, una toma de posición, no esencialista ni sublimante. Tenía en la mente la «innovación» de la que habla Jean-François Lyotard $(1979,99)$ que, a diferencia de la paralogía, trata de un «golpe,» «un coup, d'importance souvent méconnu sur-le-champ, fait sur la pragmatique du savoir.» Virginia Woolf (1986/1989, 141) también hablaba en términos similares al referirse al «poder sugestivo» de la literatura, porque cuando un texto, «un libro carece de poder sugestivo, por duro que golpee la superficie de la mente, no puede penetrar en ella.»

15 Es interesante notar que la diafonía y el organum son términos que pronto se vuelven intercambiables para referir al mismo fenómeno musical. En cambio, si también el así llamado discantus, al principio no designa otra cosa sino su equivalente latino de diafonía (es decir, organum), ya a partir del siglo XII se distingue uno del otro: 'discanto' refiere entonces a la escritura de nota contra nota, mientras que 'organum' designa al contrapunto rítmicamente ornamentado. Véase la obra, ya clásica de Gustave Reese ([1940], trad. española de 1989) sobre la música medieval, en particular 299-326 y 352-393.

16 Para una discusión sobre la polifonía musical, véase Malcuzynski 1992, 176-185.

17 ef «Las formas del tiempo y del cronotopo en la novela» (Bajtín 1989, 237-409). 


\section{Obras citadas}

Angenot, Marc. 1989. 1889. Un état du discours social. Longueuil (Québec), Préambule. Authier-Revuz, Jacqueline. 1982. «Hétérogénéité montrée et hétérogénéité constitutive.» D.R.L.A. V. Revue de linguistique (Paris). 26: 91-151.

Bajtín, Mijaíl. 1989. Teoría y estética de la novela 1975. Trad. H. Kriukova y V. Cascarra. Madrid: Taurus. Versión francesa de 1978: Esthétique et théorie du roman, trad. D. Olivier. Paris: Gallimard.

1982. Estética de la creación verbal 1979. Trad. T. Bubnova. México: Siglo XXI.

Versión francesa de 1984: Esthétique de la création verbale, trad. A. Aucouturier.

Paris: Gallimard.

—. 1986. Problemas de la poética de Dostoievski 1963, 1979. Trad. T. Bubnova. México: FCE.

- - - Versión rusa del Acto poético.

Benjamin, Walter. 1971-1983. «Histoire littéraire et science de la littérature» 1931. En Essais 1 1922-1934. Paris: DenoellGonthier: 141-148.

Cros, Edmond. 1986. Literatura, ideología y sociedad 1983. Madrid: Gredos.

Díaz-Diocaretz, Myriam. 1989. «Bakhtin, Discourse, and Feminist Theories.» Critical Studies (Amsterdam). 1. 2: 121-139.

Díaz-Diocaretz, Myriam e Iris M. Zavala, coords. 1993. Breve historiafeminista de la literatura española (en lengua castellana)./. Teoríafeminista: discurso y dijeren-. cia. Barcelona: Anthropos.

Eagleton, Terry; 1988. Una introducción a la teoría literaria 1983. Trad.). E. Calderón. México: FCE.

Ecker, Gisela, ed., 1986. Estéticafeminista. Barcelona: Icaria.

Kristeva, Julia. 1969. Sémiotyke. Paris: Seui1.

-- O 1970. «Pour une poétique ruinée.» En: La poétique de Dostoievski, trad. Y. Ko1itcheff. Paris: Seuil. 5-27.

- - O 1977. «La femme, ce n'estjamais ça» 1974. En: Polylogue. Paris: Seuil. 517-524.

--. 1979. «Letemps des femmes.» Revue 34/44 (Univ. Paris-VII). 5: 5-19. Reimpreso en Les nouvelles maladies de l'áme. Paris: Fayard. 1993: 297-331.

Lyotard, Jean-François. 1979. La condition postmoderne. Paris: Minuit.

Malcuzynski, M.-Pierrette. 1989. «The Sociocritica1 Perspective and Cultural Studies,» Critical Studies (Amsterdam). 1. 1: 1-28.

- - O 1990. «Mikhail Bakhtin and the Sociocritical Practice.»Discours social/Social Discourse (Univ. McGill, Montreal). 3.1/2: 83-98.

- - O Ed., coord. y presentación. 1991. Socioeríticas. Prácticas textuales/Cultura de fronteras. Amsterdam: Rodopi. (« hacia una semiótica social comparada:»11-28 y 153-174).

--O 1992. Entre-dialogues avec Bakhtin ou Sociocritique de la (dé)raison polyphonique. Amsterdam, Rodopi. Véase también, «Bajtín y el pensamiento polifónico.» En: Diálogos en el umbral. Ed. Ramón Alvarado. México: UAM/Nueva Imagen. En prensa.

- - O 1995a. «Feminismo y sociocrítica o la dificultad de decir 'yo.' Del 'imaginario cánonico' al 'órgano' de la literatura, en tomo a las Memorias de Leonor López de 
Córdoba,» Letras (Actas del III Congreso Internacional de Sociocrítica [nov. de 1993], Univ. Nacional, Heredia, Costa Rica, 1995). En prensa.

- 1995b. «Hacia un 'monitoring' feminista de la cultura.» En: Método y crítica: Teoría y praxis. Ed. Magda Graniela. Puerto Rico, en prensa. Versión revisada y aumentada de un artículo publicado en Revista Feminaria (Buenos Aires, 1993). 16.1 0: $16-20$.

Moi, Toril. 1988. Teoría literariafeminista 1985. Madrid: Cátedra.

Pecheux, Michel. 1975a. «Introduction au numéro 37: Analyse du discours, langue et idéologies» y, en colaboración con C. Fuchs, «Mise au point et perspectives à propos de I'analyse automatique du discours.» Langages (Paris). 37: 3-6 y 7-80. Fragmentos reimpresos en $L$ 'inquiétude du discours. Textes de Michel Pecheux, 1990. Ed. Denise Maldidier. Paris: Cendres.

- - O 1975b. Les vérités de La Palice. Paris: Maspero.

Reese, Gustave. 1989. La música en la Edad Media 1940. Madrid: Alianza.

Robin, Régine. 1994. «Hacia una sociopoética del imaginario social» 1993. En: Historia y literatura. Ed. Françoise Perus. México: Mora. 262-300.

Volshinov, Valentín N. 1992. El marxismo y lafilosofia del lenguaje 1929. Trad. T. Bubnova. Madrid: Alianza.

Woolf, Virginia. 1986, 1989. Una habitación propia 1929. Barcelona: Seix Barral. 